\title{
Effective microbial bioremediation via the multi-omics approach: An overview of trends, problems and prospects
}

\author{
Yunusa, Y.R. (D1 and Umar, Z.D. (i) 2 \\ ${ }^{1}$ Department of Microbiology, School of Postgraduate Studies, Umaru Musa 'Yar'adua \\ University, Katsina, Nigeria. \\ ${ }^{2}$ Department of Microbiology, Faculty of Natural and Applied Sciences, Umaru Musa \\ 'Yar'adua University, Katsina, Nigeria. \\ *Corresponding Author: yahayayunusariko@gmail.com; +234(0)7063966453
}

\begin{abstract}
Techno-industrial advancements the world over had led to the generation of hazardous environmental pollutants. Microbial bioremediation offers the best alternative for the removal of these pollutants. The most recent advancements in microbial bioremediation were catalyzed by the advent of various tools that enable the study microbes at levels of sophisticated detail, including genome analysis tools (genomics), protocols for analyzing expressed proteins and enzymes or proteomes (proteomics), techniques of analyzing ribonucleic acids (RNAs) transcriptomes (transcriptomics), and tools for analyzing metabolic end products/metabolomes (metabolomics). The twenty first century is witnessing an outpour of developments in the application of omics approaches in effective microbial bioremediation, thus, this paper attempts to review some of the most significant insights gained from relatively recent studies over a period of two decades (2000-2020) in the applications of multi-OMICS in microbial bioremediation, including trends and cutting-edge researches. We aim to highlight, particularly, the challenges that need to be overcome before OMICs approaches are successfully enshrined in microbial bioremediation, especially in developing countries. The strategies for overcoming such challenges, and the prospects achieved were also outlined. In the coming years, we envision further researches involving the application of multi-OMICs approach in microbial bioremediation potentially revolutionizing this field, opening up research avenues, and leading to improvements in bioremediation of polluted environment.

Keywords: Biodegradation, Bioremediation; Genomics; Multi-OMICs, OMICs techniques.
\end{abstract}

\section{INTRODUCTION}

Bioremediation can be defined as the application of living organisms, such a plants, algae and microorganisms, instead of physicochemical and mechanical approaches in the cleaning of pollutants from contaminated environments, thereby returning the polluted environments back to their normal condition (Umar et al., 2019). Bioremediation has assumed a status of necessity and urgency, in the face of environmental hazards associated with pollutants accumulating into the environments on a daily basis (Umar, 2017). Microbial bioremediation is more advantageous and applicable than phytoremediation, due to their cosmopolitan ubiquity and diverse metabolic potentialities, especially at extremes of environmental conditions where plants cannot survive (Desai et al., 2009; Umar et al., 2018a; 2018b).

Current studies in the field of microbial bioremediation focus on the use of molecular

UMYU Journal of Microbiology Research tools and OMICs techniques to study microbes at levels of sophisticated detail (Desai et al., 2009; Chikere, 2013; Haroon et al., 2013; Colin et al., 2015; Plewniak et al., 2018; Joye \& Kostka, 2020). Previously, studies on bioremediation tend to centre on the isolation and identification of microorganisms capable of biodegradation; screening them for biodegradation ability; quantitative evaluation of the degradation ability of the microbes; determining the chemical kinetics of the biodegradation process and ascertaining the intermediate and final products of biodegradation (Konneke et al., 2005; Das \& Chandran, 2010; Ma \& Zhai, 2012; Ajao et al., 2014; Karthika et al., 2014; Agarry \& Latinwo, 2015; Hazrati et al., 2015; Gieg \& Toth, 2017; Overman et al., 2017; Birch et al., 2018; Hammershoj et al., 2019; Musa, 2019; Umar et al. 2020a; 2020b). 
Nonetheless, despite the great achievements recorded in the field of microbial bioremediation using these approaches, mainly the isolation and characterization of novel microbes with potential degradation abilities from different places, globally (McDonald et al., 2006; Adebusoye et al., 2007; Singh \& Lin, 2008; Das \& Chandran, 2010; Nikhil et al., 2013; Rehman et al., 2015; Yetti et al., 2016). There had been a major shortcoming: despite the fact that microbial capability of utilizing metabolites and pollutants is virtually boundless, there are certain compounds that had been observed to be recalcitrant, and those that have not been reported to be degraded before. This leads researchers to pose questions, regarding whether new microbes and microbial capabilities for remediating these recalcitrant compounds can be isolated and identified (Esteve-Nunez et al., 2001; Singh and Nagaraj, 2007). However, the use of -omics techniques (genomics, transcriptomics, proteomics, and metabolomics), spearheaded bywhole genome sequencing technology data makes possible the identification of microbes and elucidation of functional genes degrading hitherto unreported contaminants and certain recalcitrant compounds (El-Amrani et al., 2015; Basak \& Dey, 2016). Specifically, this approach has resulted in the elucidation of novel Archaea such as the first nitrifying Archaeon (Schleper et al., 2005); the only strain in acid mine tailings capable of fixing nitrogen (Tyson et al., 2005) and an iron-oxidizing strain grouped into the novel genus called Ferrovum (Ulrich et al., 2016).

The term, meta-omics was coined to describe the applications of omics in environments, directly. This was necessitated by the widespread observations that biodegradation determinants in controlled microcosms, i.e. biodegradation experiments in the lab or in vitro and results of application of microbial communities in situ, i.e. during field trials, differ to some extent, which was attributed to spatio-temporal changes (Ma \& Zhai, 2012). Among the omics technologies, proteomics and transcriptomics are associated with the direct indicators of changes in physiological responses elaborated by microbes in response to different phenomena in the environment, either through initiation of production of responses (transcriptomics), or through the production of translation products that can directly impact the environments called proteomics (Singh \& Nagaraj, 2006)
These techniques widened, and are still widening the horizons of understanding of the molecular basis of microbial bioremediation; increasing the efficiency of in situ bioremediation techniques, and helping the redesigning of more effective techniques and approaches to microbial bioremediation of contaminated sites (Wood, 2008).

Moreover, the application of OMICs techniques had led to the discovery of novel microorganisms not previously cultured in the lab, the annotation of the genomes, metabolomes and proteomes of these microbes, and their applications in biotechnology, for enhanced microbial bioremediation (Overmann, 2010; Gutleben et al., 2018).

Through the OMICs approach, current knowledge of microbial bioremediation has increased a great deal. For instance, researchers have confidently established, through these approaches, certain structuralfunctional relationships of microbial cells or communities and applied these to bioremediation. Moreover, it had been found that a correlation exists between the abundance and expression of the functional genes in polluted areas, and the rates of microbial degradation or transformation of the pollutants, thus paving the way for improved designs of models for predicting the kinetics of microbial bioremediation (Zhou \& Fields, 2006). Understanding the OMICs

The term OMICs refers to the holistic identification and quantification of repositories of biomolecules responsible for microbial physiology and metabolism, structure and dynamics, through various techniques such as genomics, proteomics and metabolomics. The term is derived from the phrase omic which is affixed to the end of the techniques mentioned above. Moreover, the subjects of studyof each field are described as the OMEs of the OMICs, i.e. genomes, proteomes and metabolomes, for the three OMICs techniques stated before, respectively. The OMICs also include lipodomics, which is the study of microbial lipids; interactomics, which study gene-gene and protein-protein interactions; and microbiomics, which studies the genomes of whole microbiomes, i.e. microbial communities in a particular locale (Lederberg and McCray, 2001; Holtorf et al., 2002; Rathoure \& Dhatwalia, 2016; Kumari \& Kumar, 2021).

Conceptualizing the OMICs Approach

The OMICs technologies, as described earlier, encompass many aspects, including these seven major branches: 
1. Genomics: Genomics involves the utilization of high-throughput and deep sequencing tools to sequence complete microbial genomes, with rapidity and precision. Data from genomics illustrates the fine details regarding the metabolic potentialities of particular microbes and their roles in diverse ecosystems, e.g. their hydrocarbon degradation potential. Upon subsequent robust laboratory investigations, it is possible to focus on specific metabolic activities and functions of individual microbial genes (Lovely, 2003; Pan et al., 2015; Imperato et al., 2019; Oyewusi, 2021).

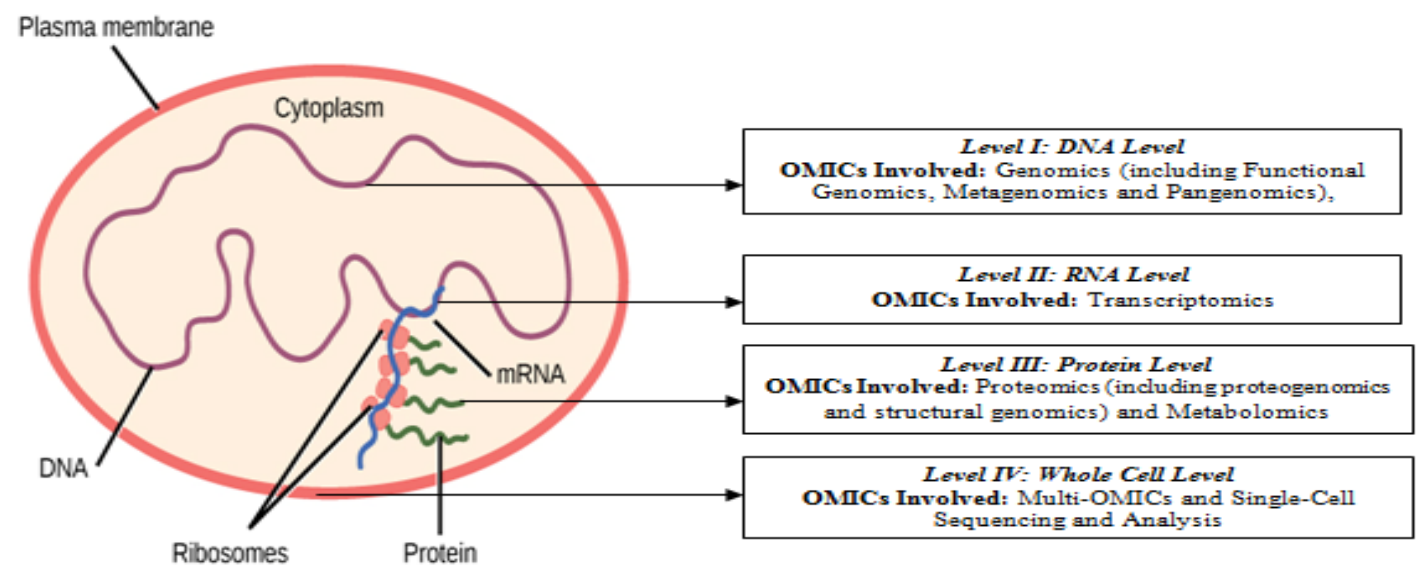

Figure 1: A simplified schematic diagram of a typical bacterial cell highlighting the areas where specific 'OMICs' are applicable. Modified from: Brainborder.com (2020)

Functional genomics, as a branch of genomics, involves the study of the functions of individual genes and their relationships with expressed metabolic products. It was said to arise due to the discovery of various genes whose function was unknown, in many genome-sequencing projects (Pan et al., 2015; Shao et al., 2019; Xiang et al., 2020). Metagenomics, on the other hand, is the genomic analysis of environmental samples, while Pangenomics studies the whole genes or genomes associated with a particular species (Singh and Nagaraj, 2007; Marchesi \& Ravel, 201; O'Connell et al., 2017).

2. Transcriptomics: This involves "studying the profiles of microorganisms by analyzing their RNA sequences". Here, gene expression and its relationship to environmental features and or turbulences are revealed. As such, with such knowledge, the active microbial players in particular microcosms, their genetic composition and their responses to environmental phenomena can be discerned. Usually, environmental disturbances, such as oil spills, trigger changes in the RNA profiles of microorganisms, and studying these changes will illustrate how microbes respond to such conditions (Singh \& Nagaraj, 2007; Yoneda et al., 2016; Gu et al., 2018).

3. Methylomics: This encompasses the investigation of how DNA methylation occurs, as it relates to the epigenetic regulation of DNA patterns, the study of which is known as epigenomics. Combined, these two switch specific genes or gene cascades on or off, in response to environmental changes or stress (Marchesi \&Ravel, 2015).

4. Proteomics: Proteomics is a terminology coined in 1995 (Wasinger et al., 1995). This involves the use of mass spectrometry analysis to disclose the protein content of cells, and how these can be affected by posttranscriptional modifications, such as phosphorylation. These changes are major mechanisms that switch many proteins on or off, which can dramatically affect their cellular functions. Subsumed under this is proteogenomics, which studies the application of proteomics for annotating genes, and structural genomics, which elaborates the 3dimensional structures of proteins through experimentation and modeling (Zhao and Poh, 2008).

5. Metabolomics: This branch of OMICs deals with the application of a spectrum of advanced analytical chemistry techniques, including nuclear magnetic resonance (NMR) spectroscopy and high-resolution mass spectrometry, such as Fourier Transform Ion Cyclotron Resonance Mass Spectrometry (FTICR-MS). These techniques are used to generate metabolite fingerprints of expressed metabolic currencies available to, produced by, and exchanged between microbes. A branch of the metabolomics is metabonomics, a quantitative measurement of the dynamic multiparametric metabolic response of living systems to pathophysiological stimuli or genetic modification (Joye \& Kostka, 2020). 
6. Meta-OMICs: Meta-OMICs is a holistic approach that combines all aspects of cell metabolism, from gene sequences to expressed metabolites, with a view to revealing the roles and functions of microbial communities synergistically interacting with one another beyond individual efforts of microbes. Furthermore, meta-OMICs gives cues regarding the relative abundance, and indirectly, roles, of species of microorganisms, their genes, protein expression products within communities in the environment (Gutleban et al., 2018).

7. Single-cell Sequencing and Analysis: Finally, in this ultimate approach, individual cells and species of microorganisms are studied; and particular genes, transcripts, etc., and associated ecosystem functions are linked to specific individuals within the microbial community, thus, the identification of most prominent hydrocarbon degraders is readily possible (Woyke et al., 2017; Joye \& Kostka, 2020; Kaster \& Sobol, 2020).

\section{Prospects of the OMICs Approach in Microbial} Bioremediation

As Zhou \& Fields (2006) have highlighted, microbial bioremediation stands to benefit from theapplication of these OMICs techniques in many respects. For example, the sequencebased metagenomics approach can serve as an index of observing microbial diversity and community dynamics of polluted environments. Likewise, proteomic approaches function as tools for the quantitative evaluation of microbial roles in the contaminated areas. The populations of microorganisms and the presence of certain genes of interest are detectable using functional gene arrays, generated via application of metagenomics, as high throughput and quantitative tools with great precision. Metaproteomics, the quantitative identification of hundreds if not a thousand proteins is also now employed (Bargiela et al., 2015; Bozinovski et al., 2016; Xu \& Zhao, 2018).

OMICs approaches in general can as well delineate the interrelationships between biomarker measurements and microbial roles in polluted environments. Moreover, prospectively, data chunks from OMICs studies can be used to hypothesize for behaviors of microbial populations, communities, etc. (Denaro et al., 2005; Roling et al., 2010; Seifert et al., 2013) The efficiency of metagenomic analyses can be increased by factoring in biochemical pathway(s) of interest and environmental conditions such assulfatereduction, methanogenic, and iron-reduction (Hadadi et al., 2020). In the near future, OMICs techniques can be utilized in improving the ability to predict geo-ecological phenomena in subsurface ecosystems, with regards to on-thefield bioremediation (McLean, 2013; Qiao et al., 2013; Ali et al., 2020). Ultimately, utilizing the profiles of functional microbial ability generated from OMICs studies into geochemical models can have enhanced predictive properties. Knowing the dominant microbial communities in degraded environments allow the adjustment of environmental conditions to favor the desired populations (Zhou \& Fields, 2006; Umar et al., 2016).

Focus on Specific OMICs and their Application in Bioremediation

\section{I: Genomics, Functional Genomics \&} Metagenomics

Genomics approaches have helped microbiologists in the molecular study of the microbial communities involved in biodegradation in great detail, and describing microbes with potential degradation ability that were not previously discovered (Liu \& Liu, 2013; Umar et al., 2017; Joye \& Kostka, 2020). A typical example of a research involving this approach is that of Liu and Liu (2013), in which the researchers described the previously unreported potential of some members of the Bacteriodes genera to carry out microbial biodegradation.

Furthermore, metagenomic studies can be targeted towards using environmental DNA (EDNA)which had been amplified using specific primers to search the presence of microorganisms capable of performing biodegradation (Vakhlu and Gupta, 2013). For instance, genes such as methane monooxygenase, methanol dehydrogenase, and ammonia monooxygenase genes are used in the identification of methanotrophic and chemolithotrophic ammonium oxidizing bacteria (Henckel et al., 2000; Singh \& Singh, 2017; Gaby et al., 2018; Thulasi et al., 2018; Wright et al., 2020). Similarly, catechol 2,3dioxygenase, chlorocatechol dioxygenase and phenol hydroxylase genes are used in screening microorganisms for biodegradation potential (Marsachi et al., 2000; Futamataet al., 2001; Lilis et al., 2010; He et al., 2016).

The use of metagenomics can also reveal species succession in polluted environs (Rodriguez-R et al., 2015). Using metagonomics studies spread across specific time intervals, Alcanivorax and Marinobacter spp., both belonging to the Gamma proteobacteria, that had earlier dominated the microbial community of a Deepwater spill buried in a Florida beach, for at least three months, degrading mostly the alkanes, were shown to be succeeded by members of the Alphaproteobacteria, specifically, Hyphomonas and Parvibaculum, which are capable of biodegrading aromatic 
compounds. Biodegradation was finished in a year, with the beach's population then turning back to its original form, with the biodegraders suppressed to the low levels they were in hitherto the pollution (Huettel et al., 2018)

Functional genomics have also highlighted the role of Marine Oil Snow (MOS) in the biodegradation of spilled petroleum hydrocarbons in marine environments. Marine Oil Snows form from the aggregation of microbial communities, typically bacteria, around oil particles, encasing them in biosurfactants or transparent exopolymers and biomass, forming 'snows' which then descend to the seafloor (Ziervogel et al., 2012). This mechanism played an important role in the removal of oil from the water surface during the Deepwater spill (Vonk et al., 2015). The lipase activity of MOS particles is thought to confer on them the potential to serve as ready avenues for oil degradation (Gutierrez et al., 2018). The MOS contains microbial communities that are distinct from the surrounding water column and specialized for breaking down oil (Umar and Bashir, 2014). In particular, Colwellia and Marinobacter spp. (as well as other Alteromonas spp.) are prevalent in these particles, with the unique capacity to rapidly degrade oil in cold, deep marine environments (Gutierrez et al., 2018).

Another application of functional genomics is the elucidation of candidate genes from microbial consortia for previously obscure roles, an example of which is the study by Shin et al. (2019) which described the anaerobic degradation of polycyclic aromatic hydrocarbons via anaerobic pathways, such as sulfate reduction, from enriched microbial consortia from the Gulf of Mexico.

The use of genomic approaches can also reveal the coupling of certain elements involved in biogeochemical cycling with microbial biodegradation, such as nitrogen, phosphorus, sulphur, iron, and other trace metals, the genes for the metabolism of which are shown to be enriched during biodegradation (Bashir et al., 2014; Rodriguez-R et al., 2015). This insight is useful in at least two ways, one is devising approaches for 'fertilizing' contaminated environments with those elements to facilitate biodegradation, and two, as evidence for the roles of certain metal cofactors, such as lanthanides, in serving as cofactors in biodegradation of methylotrophs (Shiller et al., 2017).

Another area for potentially applying metagenomics is in the characterization of genes involved in biodegradation, as it is thought that $30-50 \%$ of those genes remain uncharacterized. Identifying these genes is particularly important as they may be involved in degrading a broader range of substrates, a smaller subset of substrates or perform an entirely new function (Igeno et al., 2019; Joye \& Kostka, 2020; Salvador et al., 2020; Santero \& Diaz, 2020).

\section{Transcriptomics}

The transcriptome describes the total of the transcription products of a microorganism, as such, they are critical bridges between genomics, proteomics, and cellular phenotypes. Transcriptomics is affected by changes in the genome, due to regulations in genes, manifested by the microbe, to adapt to varying environmental conditions, and the study of these is best done using DNA microarray studies, which enable, by and large, studies of individual messenger RNAs (mRNAs) (Dharmadi\& Gonzalez, 2004; Diaz, 2004).

Practical, in situ applications of transciptomics in bioremediation include the use of DNAmicroarray technologies in studying soils artificially contaminated with naphthalene (Cho and Tiedje, 2002).These DNA-microarray studies can generate the whole genome transcribed products. Subsequently, the data gathered can be assembled into a diagram of the regulatory mechanisms governing bioremediation in microbes (Seshadri et al., 2005; Ladezma-Villaneuva et al., 2018; Wang et al., 2020). Furthermore, transcriptomics studies can involve the analysis of gene expression products of microbial communities following changes in certain environmental factors (Dennis, 2006), for instance, varying oxygen concentration results in more than 100 genes in Bacillussubtilis cultivated anaerobically (Ye et al., 2000).

Greene and Voordouw (2003), in the same vein, utilized transcriptomics in studying how environmental microbial communities respond to stress, by studying functional 'stress genes'. Another study by Kuhner et al. (2005), studied the microbial bioremediation properties of anaerobic toluene and ethyl benzene degradation, where a global gene expression analysis helps in the elucidation of mechanisms for regulating many unidentified genes involved in the catabolism of alkylbenzenes. In another study, it was shown that upon exposure to the toxic compound o-xylene, RhodococcusopacusR7 elaborated 542 differently expressed genes for stress tolerance, osmotic regulation and central metabolism (Zampoli et al., 2020). 
In another study, the same bacterium, and another member of the same genus, R.aetherivorans had also been reported to survive a wide spectrum of stresses ranging from osmotic and oxidative stress to the presence of antibiotics, metals and other toxic compounds (Capelletti et al., 2016).

\section{III: Proteomics}

Proteomics presents a comprehensive summary of the expressed phenotype of a microbial species, better than the genome can (Singh and Nagaraj, 2007). Traditionally, the tools used for proteomics analyses include multidimensional Poly Acrylamide Gel Electrophoresis and Mass Spectrometry, however, recent improvements have resulted into the advent of multidimensional protein identification technology (mudPIT) as a technique for proteomics (Paolettiet al., 2004).

Proteomics had been shown to play a key role in the detection of biomarkers for identifying environmental pollutants, such as polycyclic aromatic hydrocarbons (Aardema \& McGregor, 2002). It is known that in the bioremediation of polycyclic aromatic hydrocarbons, alterations to the microbe involved in the process results in drastic changes in cell surface receptors and proteins, hence, by monitoring these using proteomics, significant changes can readily be detected (Singh and Nagaraj, 2007). When the peptides have been successfully removed from the soil environment, they are then identified by subjecting them to Matrix-Assisted Laser Desorption Ionisation Time-of-Flight Mass Spectrometry (MALDI-TOF), where the respective peptide fingerprints will be translated into specific proteins. Additionally, it is now possible to use MALDI-TOF-MS directly in situ, using an alternative developed called Surface-Enhanced Laser Desorption Ionisation Tine-of-Flight Mass Spectrometry, where the MALDI apparatus is incorporated onto a chip that can directly interact with sample fractions from environments (Knigger et al., 2004).

Another technique being considered is LiquidChromatography Mass Spectrometry (LC-MS), which is of particular use in aquatic analyses, to detect contaminants that can possibly pollute the water, however, in the microbial bioremediation arena, this technique has been extended to be used in analyzing the metabolites signaling biodegradation of pesticides, surfactants, pharmaceutical wastes, etc. (Joo and Kim, 2005).

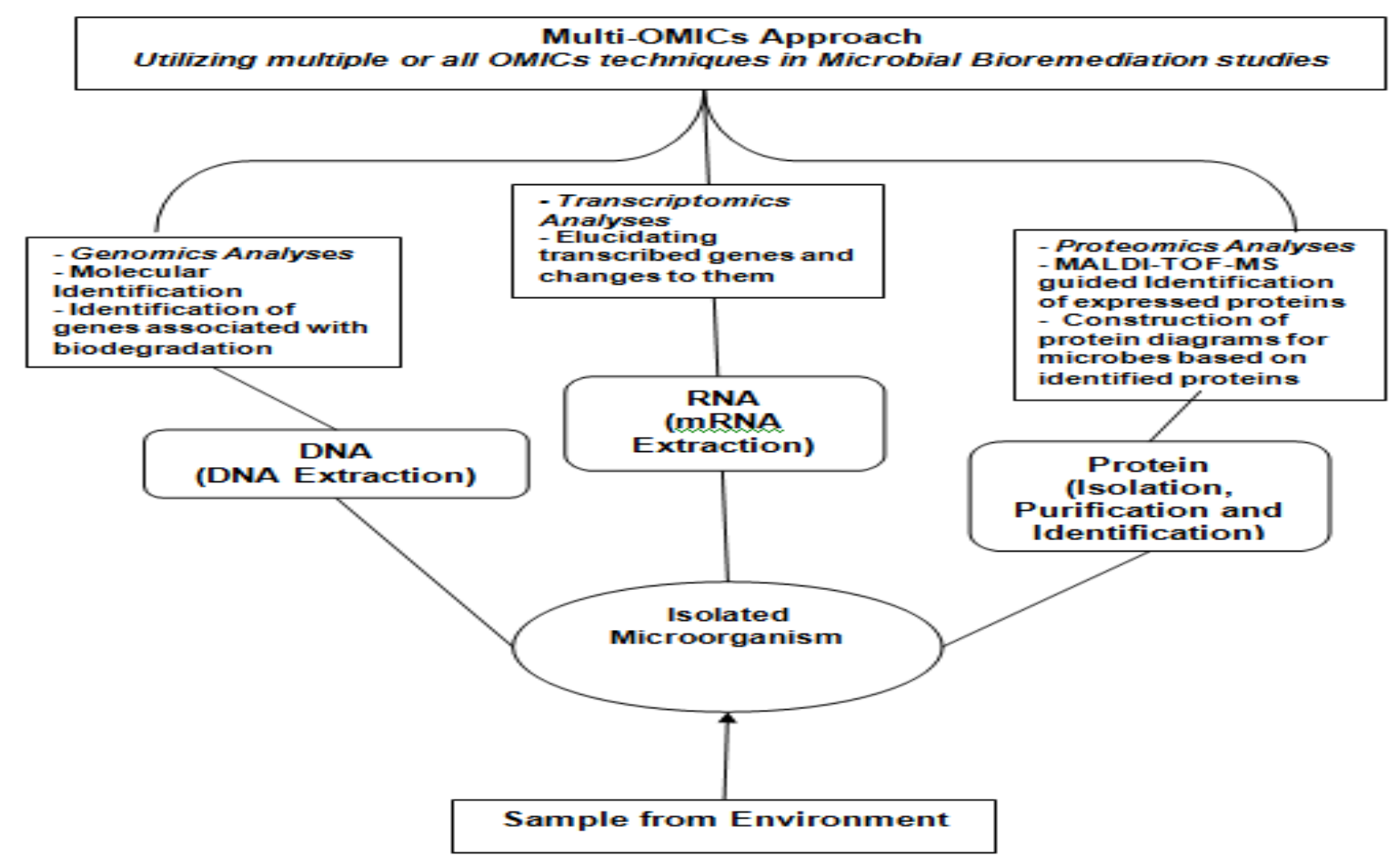

Figure 2: Proposed scheme for an OMICs approach to microbial bioremediation (Modified from: Singh and Nagarajan, 2007).

Proteomics is directly linked to microbial biodegradation because protein expression, at least in some genes, is regulated by certain responses to external environmental stimuli, such as presence of pollutants (Wilkins et al., 2001; Kim et al., 2002). 
Separate, but related studies had practically demonstrated this. For instance, Wang et al. (2000) demonstrated that in the degradation of pyrenes, a protein of mass $81 \mathrm{kDa}$ is involved, which resembles a catalase-peroxidase enzyme complex. Khan et al. (2001), on the other hand, reported that growing a Mycobacterium sp. on phenanthrene, dibenzothiopene and pyrene led to the induction and overexpression of six major proteins, which the authors identified using 2-D-Gel Electrophoresis.

In another study, various proteins were indicated as potential indicators of enzymatic degradation of pyrene, e.g. two-ring hydroxylating doxygenases, by a species of Mycobacterium (Krivobok et al., 2003). Moreover, Kim et al. (2004) were able to generate a library of about 20 proteins elaborated by a strain of Mycobacterium vanbaalenii, when cultured in a high molecular weight PAHs-rich environment.

In yet another study, Santos et al. (2004) constructed a protein reference map for Pseudomonas putida KT2440 grown in high, but tolerable concentrations of phenol, where 81 proteins where expressed, with 68 being upregulated (including proteins involved in general and oxidative stress response, cell envelope and fatty acid biosyntheses, energy utilization, cellular transport, among others), and 13 being down-regulated (nucleotide biosynthesis and cell motility proteins).

In the future, it has been suggested that proteomics studies should target how the expression of proteins changes with variations in environmental factors, presence of toxins, etc. Such studies may hopefully elucidate signature proteins key in biodegradation activities of specific microorganisms. Furthermore, the combination of transcriptomics and proteomics has the potential to illuminate new pathways for aerobic and anaerobic biodegradation, and this can be doneusing protein microarray-based approaches (Namasivayam, 2013).

Finally, proteomics researches are receiving significant impetuses through the development of cutting-edge techniques, such as the recent approach of studying the translation products of microorganisms through the BONCAT approach (Bioorthogonal Noncanonical Amino Acid Tagging), which has the potential to be coupled with multi-OMICs to facilitate acquisition of news insights into patterns of microbial biodegradation of pollutants Hatzenpichler et al. (2016).

IV: Metabolomics

Through metabolomics-related studies, the diversity of microorganisms and their previously unknown capacities for microbial biodegradation can be understood. Such studies can also lead to understanding roles that are previously unknown for specific microbial genera or species. For instance, the bacterium, Cycloclastus sp. is previously known to degrade polycyclic aromatic compounds at low temperatures, (Dubinsky et al., 2013), however, later, it was shown to have the capability of degrading ethane, propane and butane via aerobic oxidation; at both the surface and sediments, showing a more versatile tolerance to temperature fluctuations (Joye \& Kostka, 2020).

Recent studies (for instance, Huettle et al., 2018; American Association of Microbiology, 2020) had also enabled the appreciation of certain species having diversified metabolomic profiles, such as Marinobacter sp. (Huettel et al., 2018), and in particular, Marinobacter hydrocarbonoclasticus, which has been shown to possess a repertoire of metabolic capabilities for growth in high and low salinity environments, using both oxygen and nitrates or nitrites as electron acceptors, and oxidizing both alkanes and aromatics. This biogeochemical opportunitroph, as it has been described, can exist in a spectrum of environments and carryout numerous functions (Gaby et al., 2018; Joye \& Kostka, 2020).

Likewise, metabolomics have helped in elucidating novel species of microorganisms widely distributed across the globe, and sharing remarkable functions. One such organism is the bacterium, "Candidatus Macondimonas diazotropica", (Karthikeyan et al., 2019) which has been shown to account for about one-thirds of the microbial community degrading oil spilled on shores during the mid to late phases of the degradation (Weiman et al., 2021; Karthikeyan et al., 2019). A key feature of the bacterium is its ability to fix nitrogen, thus, it can survive even in low-nitrogen environs (Karthikeyan et al., 2019). 
Table 1: Summary of some applications of OMICs approaches in microbial bioremediation studies

1. Explanation of how environmental DNA which had been amplified using specific primers can be used to search the presence of microorganisms capable of performing biodegradation, e.g. using genes such as methane monooxygenase, methanol dehydrogenase, and ammonia monooxygenase genes to identify methanotrophic and chemolithotrophic ammonium oxidizing bacteria; and catechol 2,3-dioxygenase, chlorocatechol dioxygenase and phenol hydroxylase genes can be used in screening microorganisms for biodegradation potential.

2. Revealing microorganisms with previously unknown biodegradation potential

Mesarch et al. (2000)

Henckel et al. (2000)

Futamata et al. (2001)

Vakhlu \& Gupta (2013)

Liu \&Liu (2013)

3. Illumination of how certain elements involved in biogeochemical cycling (e.g. nitrogen, phosphorus, sulphur, iron, and other trace metals), are coupled with microbial biodegradation, how genes for their metabolism are enriched during biodegradation; potential for fertilizing contaminated sites and their roles as cofactors (e.g. in biodegradation of methylotrophs).

4. Elucidation of succession between microbial species (e.g. Alcanivorax, Hyphomonas, Parvibaculum and Marinobacter spp.), how they evolve over time in polluted environments, their enrichment, how they biodegrade alkanes and oraromatics and how they become suppressed after the completion of the biodegradation, through metagenomics analyses.

5. Description of the role, formation and function of Marine Oil Snow (MOS) in biodegradation of spilled petroleum hydrocarbons in marine environments, the microorganisms involved in the process, (Colwellia and Marinobacter spp.; Alteromonas spp.) and the roles they play in bioremediating the Deepwater spill.

6. Highlighting of candidate genes from microbial consortia from the Gulf of Mexico which carryout previous undescribed functions, e.g. the anaerobic degradation of polycyclic aromatic hydrocarbons via anaerobic pathways, such as sulfate reduction.

7. Characterization of genes involved in biodegradation - 30-50\% of which remain uncharacterized - including those potentially involved in degrading a broader or smaller range of substrates, a smaller subset of substrates, or perform entirely new degradation functions.

II. Transcriptomics: studying the gene expression products, in form of mRNAs, to determine changes to genomes, and genome functions.

1. Application of DNA microarrays in studying soil artificially contaminated with naphthalene.

2. Studies of mRNAs to elucidate previously unidentified genes involved in the degradation of alkylbenzenes.

III. Proteomics: Study of the translation products of expression of genes, their modification, and how they affect cellular response, with regards to environmental alterations 
1. Characterization of an $81 \mathrm{kDa}$ protein resembling catalase-peroxidase enzyme complex elaborated in the presence of pyrenes.

2. Induction and overexpression of six major proteins identified using 2-D-Gel Electrophoresis, from a Mycobacterium sp. grown on phenanthrene, dibenzothiopene and pyrene.

3. Generation of a library of some 20 proteins elaborated by a strain of Mycobacterium vanbaalenii cultured in a high molecular weight PAHs-rich environment.

4. Construction of a protein reference map for Pseudomonasputida KT2440 grown in high, but tolerable concentrations of phenol, and monitoring the expression, up and down regulation of the proteins.

5. Analysis of metabolic intermediate and final products indicative of biodegradation of pesticides, surfactants, pharmaceutical wastes, etc.

6. Description of changes in protein expression and how they vary with environmental factors, presence of toxins, etc., as such identifying signature proteins key in biodegradation activities of specific microorganisms.

7. Combination of transcriptomics and proteomics to illuminate new pathways for aerobic and anaerobic biodegradation using protein microarray-based approaches.

8. Elucidation of how translation products of microorganisms are studied through the BONCAT approach (BioorthogonalNoncanonical Amino Acid Tagging), coupled with multi-OMICs to facilitate acquisition of news insights into patterns of microbial biodegradation of pollutants.

Wang et al. (2000)

Khan et al. (2001)

Kim et al. (2004)

Santos et al. $(2004)$

Joo \& Kim (2005)

Namasivayam, (2013)

Hatzenpichler et al. (2016)

Hatzenpichler et al. (2016)

1. Revealing the diversity of microorganisms, and explaining previously unknown capacities of microbes for microbial biodegradation, with specificity up to the genera and even species level, e.g. Cycloclastus sp., previously known to degrade polycyclic aromatic compounds at low temperatures, had been shown to be capable of degrading ethane, propane and butane, aerobically or anaerobically, across a wide temperature range.

2. Identification of diversified metabolomic profiles of microbes such as Marinobacter sp. and in particular, the 'biogeochemical opportunitroph':Marinobacterhydrocarbonoclasticus, which has been shown to possess a repertoire of metabolic capabilities for growth in high and low salinity environments, using both oxygen and nitrates or nitrites as electron acceptors, and oxidizing both alkanes and aromatics).

3. Elucidation of novel species of microorganisms widely distributed across the globe, having remarkable biodegradation capabilities, e.g. the bacterium "Candidatusmacondimonasdiazotropica", which can take up to about one-thirds of the microbial community degrading oil spilled on shores during the mid to late phases of the degradation, and is also capable of nitrogen fixation, hence can survive even in low-nitrogen environs.

Dubinsky et al. (2013)

Gaby et al. (2018).

Huettel et al. (2018)

Karthikeyan et al. (2019)

Weiman et al. (2021) 
V. Multi-OMICs: Harmoniously leveraging the various OMICs techniques in concordance, towards better studies of microorganisms involved in bioremediation, and their metabolism.

1. Studying the interrelated links between metabolic pathways for degradation of petroleum hydrocarbons, and how each specie in this 'microbial conglomerate' specifically contributes to 'division of labor'.

2. Tracing the fate of a specified substrate within a diverse microbial community, thus characterizing pathways for its degradation, potentially new microbial species, and the unknown functions of known degraders, through Stable Isotope Probing (SIP).

3. Explaining how microbial communities involved in biodegradation change before and after the occurrence of spills, i.e. before spills, these communities may be present in low amounts, however, spills trigger their rapid proliferation, domination of the microbiome of the polluted place, and expression of multiple metabolic pathways depending on the nature of the pollution and other environmental factors.

4. Identification of pollution-related biomarkers including predictive biomarkers (e.g. first responders in spillaffected environs that are indicative of potential for spills, leaks, etc.), diagnostic biomarkers (which indicate the presence of contamination in environments) and therapeutic biomarkers (which are used in restoration and reclamation of spill-affected environments)

5. Studying soil microbial species' diversity or consanguinity, their genetic capabilities and potential, their inherent and expressed metabolic profiles; and their potential application in diverse environments.

Mason et al. (2012)

Gutierrez et al. (2013)

Dubinsky et al. (2013)

Rodriguez-R et al. (2015)

Shin et al. (2019)

Joye \& Kostka (2020)

Dini-Andreoteet al. (2012)

Fierer et al. (2012)

Umar et al. (2020) 


\section{V: Multi-OMICs: The Combination of Multiple OMICs Techniques}

The application of multi-OMICs in bioremediation can best be illustrated by the aftermaths of the case of the Deepwater Horizon spill. For instance, Mason et al. (2012) used metagenome, meta-transcriptome and single-cell sequencing analyses to reveal the overall microbial response of the multitude of microorganisms to the spill, revealing the spread of metabolic pathways across multiple community members, and using metatranscriptome and metagenome data to identify the role and function of each species in the pathway.

The application of multi-OMICs approach is also seen in Stable Isotope Probing (SIP), where the fate of a specified substrate is traced within a diverse microbial community, thus characterizing pathways for its degradation, potentially new microbial species, and the unknown functions of known degraders (Gutierrez et al., 2013). The technique is typically applied in identifying active microorganisms without having to resort to cultivation, and this can be important in screening microbes with potential to be used in bioremediation (Chen et al., 2010). This technique has proven particularly successful in the identification of uncultivable bacteria capable of degrading pesticides (Jiang et al., 2018).

The multi-OMICs approach have also helped in understanding the evolution of microbial communities involved in biodegradation before and after the occurrence of spills. Before spills, these communities may be present in low amounts; however, spills trigger their rapid proliferation, domination of the microbiome of the polluted place, and expression of multiple metabolic pathways depending on the nature of the pollution and other environmental factors (Dubinsky et al., 2013; Rodriguez-R et al., 2015; Shin et al., 2019).

Biomarkers are also identified using multiOMICs approach, including predictive biomarkers (e.g. first responders in spillaffected environs that are indicative of potential forspills, leaks, etc.), diagnostic biomarkers which indicate the presence of contamination in environments and therapeutic biomarkers which are used in restoration and reclamation of spill-affected environments (Joye \& Kostka, 2020).

Summarily, microbiologists were able to apply the OMICs tools and directly study the intricacies of microbial interrelationships in their habitats, from both oil-contaminated and uncontaminated water and sediment samples. These enable scientists to know the microbial reactions to hydrocarbon contamination and the methodological underpinnings of microbesassisted environmental reclamation, in unparalleled detail (Chikere, 2013; Rathoure \& Dhatwalia, 2016; Kaster \& Sobol, 2020; Kumari \& Kumar, 2020; Santero \& Diaz, 2020).

Problems/Challenges of OMICs Approaches Despite the numerous benefits and prospects of the application of the OMICs in microbial bioremediation, there are still certain challenges needing to be addressed before the OMICs can reach their full potential, especially in developing countries. Such challenges, as highlighted by Gutleban et al. (2018), Chakraborty et al. (2012), Ma \& Zhai (2012); Zhou \& Fields, (2006) \& Lemos et al. (2003), include:

1. There is the need to standardize reference chemicals for OMICs studies, particularly metabolomics. Corollary to this is the establishment of reference databases, to obviate the danger of generation of metabolites whose structure might be unknown.

2. In transciptomics, the presence of contaminants may prevent perfect hybridization, degrade the quality of the RNA and prevent successful isolation of the mRNA from soil.

3. These techniques and approaches are still in their introductory and developmental phase. Thus, the consistent demonstration of their applicability in various environments remains to be done, and needs time, and research efforts.

4. OMICs application in microbial bioremediation is challenged by ecological questions that are interwoven with other bioremediation approaches, such as discrepancies in microbial diversity, functional redundancy, stability, environmental micro-heterogeneity, genetic micro-diversity, and ecotypes. Such variations may lead to differences in bioremediation rates between organisms, which need to be separately and consistently evaluated.

5. Microbial diversity, association with adaptation of various microorganisms to multifarious conditions, especially in soil and aquatic environments, may present a challenge to OMIC approaches, especially in terms of tremendous data generation and information overload.

6. Not all genes are detected by transcriptomic studies, only genes from species and populations contributing to $>5 \%$ of the microbiome are detectable, thus, certain functional genes not reaching this critical threshold are not detectable. 
Accurate generalization from data of specific populations needs the careful observance of many desired populations, concurrently and covering large areas, over a long period. This endeavor is tasking to both the researcher and resources.

7. Factors that may affect the distribution of microorganisms in spoilage-affected environments, apart from their ability to tolerate the contaminants, e.g. interspecie interactions, such as competition, need to be taken into consideration.

8. Novel biomarkers need to be developed for enhancing the identification of microbial populations in spoilage-affected environs.

9. There is the need for further researches to make OMICs techniques robust, convenient and affordable.

10. There is a shortage of computational resources especially in developing countries, without with ever-increasing amounts of data cannot be sufficiently crunched, thus hindering overall bioremediation prospects.

11. Many microorganisms whose DNA, mRNA products, etc. were isolated from environments, however, they cannot be cultured in the lab, even though significant progress is being made in this area.

12. Certain microorganisms exhibit low rates of biodegradation in the environment, even though OMICs studies have characterized their potentialities.

Strategies for Ameliorating these Drawbacks

1. Generation of Standard Operation Procedures (SOPs) for genomic and metabolomics analyses, including appropriate protocols for genomic extraction and exact chemicals to be used in metabolomics analyses, to ensure methodological uniformity and homogeneity.

2. Consistent updating of reference databases to ensure that discovered proteins and enzymes are appropriately matched.

3. Accurate kits that minimize the interference of environmental contaminants and ensure precise genomic extraction should be employed for recovery of genetic material. Kits such as Power Lyzer Power Soil Power Microbiome RNA Isolation Kit, Master Pure RNA Purification Kit, RNA Power Soil Total RNA Isolation Kit, One Step PCR Inhibitor Removal Kit, RNeasy Mini Kit need to be improved (Lim et al., 2016).

4. Continuous research in variegated environments is necessary in establishing the validity and suitability of all OMICs approaches to diverse microbial groups. This is especially necessary for transcriptomics, metabolomics and multi-OMICs.
5. There is the need for widening the focus of OMICs approaches areas beyond few strains of microorganisms, to counteract microbial species diversity. Likewise, samples and culture conditions should reflect wide physiochemical ranges (temperature, $\mathrm{pH}$, amongst others)

6. Especially in developing countries, genetic and bioinformation data crunching facilities should be provided, and microbiologists should be brought up-to-date with bioinformatics techniques, to ensure a hitch-free analyses of the data generated from OMICs studies.

7. Specificity of detection technologies should be enhanced to ensure that genes below current minimal thresholds are detectable and analyzable. This will create an avenue for elucidation of novel genes with yet unknown properties and capabilities.

8. Bioremediation studies involving OMICs approaches need to cover large areas, over expanded time periods, and need to be followed up in installments. This requires increased funding from the government and concerned agencies, sustained focus and use of improved and up-to-date methodologies from the researchers.

9. Microbial ecology of contaminated sites needs to be studied in details, to accommodate inter and intra species interactions, mutualism and competition, as these factors can directly hinder or bolster bioremediation in situ and ex situ.

10. Development of novel and diverse biomarkers for enhanced environmental monitoring is necessary in OMICs studies, as currently available biomarkers are not sufficient.

11. Data sharing and comparison need to be encouraged across different laboratories, experiments, sites and research groups the world over. Thus, national and regional databases may be setup across the nation and region which can be distributed in an openaccess.

12. Development of novel culture media for culturing microbes using OMICs techniques to enhance understanding of microbes in bioremediation for the potential applications in future.

13. The OMICs tools should be utilized in strain improvement techniques and microbial consortia, as opposed to single strains for enhanced bioremediation potentials.

14. Increased funding for bioremediation researches. Governmental and nongovernmental organizations need to collaborate like the National Oil Spill Detection and Response Agency, Federal Ministry of Environment among others. 
15. Conferences, workshops, retreats, seminars, symposia and related events dealing with OMICs approaches to biodegradation should be organized to facilitate sharing of knowledge, presenting new protocols, techniques, insights, apparatuses, inventions amongst others.

\section{CONCLUSION}

The application of OMICs in bioremediation is a current technique, full of promising potentials. Such include improved geo-prediction properties, enhanced bioremediation potentials. Future trends in bioremediation are expected to be fueled by synthesis of data from

\section{REFERENCES}

Aardema, M. J. \& MacGregor, J. T. (2002). Toxicology and genetic toxicology in the new era of toxic genomics: impact of proteomics technologies.Mutation Research, 499, 13-25.

Adebusoye, S. A., Ilori, M. O., Amund, O. O., Teniola, O. D. \& Olatope, S. O. (2007). Microbial degradation of petroleum hydrocarbons in a polluted tropical stream. World Journal of Microbiology and Biotechnology, 23(8), 1149-1159.

Agarry, S. \& Latinwo, G.K. (2015). Biodegradation of Diesel Oil in Soil and Its Enhancement by Application of Bioventing and Amendment with Brewery Waste Effluents as Biostimulation-Bioaugmentation Agents. Journal of Ecological Engineering, 16:82-91.

Ajao, A.T., Yakubu S.E., Umoh V.J. and Ameh J.B. (2014).Enzymatic Studies and Mineralization Potential of Burkholderia cepacia and Corynebacterium kutscheri Isolated from Refinery Sludge.Journal of Microbiology Research, 4:29-42.

Ali, N., Dashti, N., Khanafer, M., Al-Awdahi, H. \& Radwan, S. (2020). Bioremediation of soils saturated with spilled crude oil. Scientific Reports, 10, Article 1116.

Bargiela, R., Herbst, F-A., Martinez-Martinez, M., Seifert, J., Rojo, D., Capello, S., Genovese, M., Crisafi, F., Denaro, R., Cherikova, T. N., Barbas, C., von Bergen, M., Yakimov, M. M., Ferrer, M. \& Golyshin, P. N. (2015). Metaproteomics and metabolomics analyses of chronically petroleumpolluted sites reveal the importance of general anerobic processes uncoupled with degradation. Proteomics, 15(20), 3508-3520.

Basak, B. \& Dey, A. (2016). Chapter 9: Bioremediation approaches for

UMYU Journal of Microbiology Research current studies, modeling and biosimulation analyses, standardization of methodologies, tools and techniques, use of novel biomarkers and leveraging the multi-OMICs approach toward superior bioremediation studies. Following the use of a complementary approach that harnesses OMICs tools vis-à-vis cellular biochemistry, microbial ecology, physiology and metabolism, in the near future, it is envisioned that OMICs tools will propel microbial bioremediation into a revolutionary phase characterized by detailed data gathering and enhanced efficiency in bioremoval of contaminants from polluted environments.

recalcitrant pollutants: Potentiality, successes and limitation. In A. Rathoure \& V. Dhatwalia (Eds.), Toxicity and waste management using bioremediation ( $1^{\text {st }}$ ed., pp 178-197). IGI Global.

Bashir, A., Umar, Z.D., and Steve, J.O. (2014): Comparative analysis of Pneumosiderosis among different metal workers in Malumfashi, Katsina, Nigeria. International Journal of Scientific and Engineering Research, 5(6): 1429-1436.

Birch, H., Hammershoj, R. \& Mayer, P. (2018). Determining biodegradation kinetics of hydrocarbons at low concentrations: Covering 5 \& 9 orders of magnitude of $\mathrm{K}_{\mathrm{ow}}$ and $\mathrm{K}_{\mathrm{aw}}$. Environmental Science \& Technology, 52(4), 2143-2151.

Bozinovski, D., Taubert, M., Kleinsteuber, S. \& Richnow, H. H. (2014). Metaproteogenomic analysis of a sulfate-reducing enrichment culture reveals genomic organization of key enzymes in the $\mathrm{m}$-xylene degradation pathway and metabolic activity of proteobacteria. Systematic and Applied Microbiology, 37, 488-501.

Brainborder.com (2020). Epigenetic, transcriptional, post-transcriptional, translational and post-translational levels.https: / / brainbrooder.com/lesson /428/16-1-2-sectionsummary/exercise/2274/epigenetictranscriptional-post-transcriptionaltranslational-and-post-translationallevels.

Capelletti, M., Fedi, S., Zampolli, J., Di Canito, A., D’Ursi, P. \& Orro, A. (2016). Phenotype microarray analysis may unravel genetic determinants of the stress response by Rhodococcusaetherivorans BCP1 and

$$
\text { www.ujmr.umyu.edu.ng }
$$


Rhodococcus opacus R7. Research in Microbiology, 167, 766-773.

Chakraborty, R., Wu, C. H. \& Hazen, T. C. (2012). Systems biology approach to bioremediation. Current Opinion in Biotechnology, 23, 483-490.

Chen, Y., Vohra, J. \& Murell, J. C. (2010). Applications of DNA-Stable isotope probing in bioremediation studies. Methods in Molecular Biology, 599, 129-139.

Chikere, C. (2013). Application of molecular microbiology techniques in bioremediation of hydrocarbons and other pollutants. British Biotechnology Journal, 3(1), 90-115.

Cho, J.C. \& Tiedje, J.M. (2002). Quantitative detection of microbial genes by using DNA microarrays. Applied Environmental Microbiology, 68, 14251430.

Colin, P. Y., Kintses, B., Geilen, F., Miton, C. M., Fischer, G. \& Mohamed, M. F. (2015). Ultrahigh-throughput discovery of promiscuous enzymes by picodroplet functional metagenomics. Nature Communications, 6, Article 10008.

Das, N. \&Chandran, P. (2010). Microbial degradation of petroleum hydrocarbon contaminants: An overview. Biotechnology Research International, 2011, Article 941810.

Denaro, R., D’Aria, G., Di marco, G. \& Genovese, M. (2005). Assessing terminal restriction fragment length polymorphism sustainability for the description of bacterial community structure and dynamics in hydrocarbonpolluted marine environments. Environmental Microbiology, 7, 78-87.

Dennis, P., Edwards, E. A. \& Liss, S. N. (2003). Monitoring gene expression in mixed microbial communities by using DNA microarrays. Applied Environmental Microbiology, 69, 769-778.

Desai,C., Pathak, H.\&Madamwar, D. (2009). Advances in molecular and "-Omics" technologies to gauge microbial communities and bioremediation at xenobiotic/anthropogen contaminated sites. Bioresource Technology, 101(6), 1558-1569.

Dharmadi, Y. \& Gonzalez, R. (2004). DNA microarrays: experimental issues, data analysis, and application to bacterial systems. Biotechnology Progress, 20, 1309-1324.

Diaz, E. (2004). Bacterial degradation of aromatic pollutants: a paradigm of metabolic versatility. International Microbiology, 7, 173-180.

Dini-Andreote, F., Andreote, F. D., Ara-ujo, W. L., Trevors, J. T. \& Elsas, J. D. (2012). Bacterial genomes: habitat specificity and uncharted organisms. Microbial Ecology, 64, 1-7.

Dubinsky, E.A., Conrad, M. E., Chakraborty, R., Bill, M., Borglin, S. E., Hollibaugh, J. T., Mason, O. U., Piceno, M. Y., Reid, F. C., Stringfellow, W. T., Tom, L. M. Hazen, T. C. \& Andersen, G. L. (2013). Succession of hydrocarbon-degrading bacteria in the aftermath of the Deepwater Horizon oil spill in the Gulf of Mexico. Environmental Science and Technology, 47, 10860-10867.

El-Amrani, A., Dumas A-S., Wick, L. Y., Yergeau, E. \& Berthome, A. (2015). Omics insights into PAH degradation toward improved green remediation biotechnologies. Environmental Science and Technology, 49(19), 11281-11291.

Esteve-Nunez, A., Caballero, A. \& Ramos, J. L. (2001). Biological degradation of 2,4,6trinitrotoluene. Microbiology and Molecular Biology Reviews, 65, 335-52.

Gaby, J. C., Rishishwar, L., ValderramaAguirre, L. C., Green, S. J., Valderrama-Aguirre, A., Jordan, I. K. \& Kostka, J. E. (2018). Diazotroph community characterization via a highthroughput nifH amplicon sequencing and analysis pipeline. Applied Environmental Microbiology, 84, Article e01512-17.

Gieg, L. M. \& Toth, C. R. A. (2017). Signature metabolite analysis to determine in-situ anaerobic hydrocarbon biodegradation. In M. Boll (Ed.), Anaerobic utilization of hydrocarbons, oils and lipids ( $1^{\text {st }} \mathrm{ed}$., pp. 1-30).Springer.

Greene, E. A. \& Voordouw, G. (2003). Analysis of environmental microbial communities by reverse sample genome probing. Journal of Microbiology Methods, 53, 211-9.

Gu, Q., Wu, Q., Zhang, J., Guo, W., Ding, Y., Wang, J., Wu, H., Sun, M., Hou, L., Wei, X. \& Zhang, Y. (2018). Isolation and transcriptome analysis of phenoldegrading bacterium carbon sand filters in full-scale drinking water treatment plant. Frontiers in Microbiology, 9, Article 2162.

Gutierrez, T., Morris, G., Ellis, G., Bowler, B., Jones, M., Salek, K., Mulloy, B \& Teske, A. (2018). Hydrocarbon-degradation an MOS-formation capabilities of the dominant bacteria enriched in sea 
surface oil slicks during the Deepwater Horizon oil spill. Marine Pollution Bulletin, 135, 2015-215

Gutierrez, T., Singleton, D. R., Berry, D., Yang, T., Aitken, M. D. \& Teske, A. (2013). Hydrocarbon-degrading bacteria enriched by the Deepwater Horizon oil spill identified by cultivation and DNASIP. ISME Journal, 7, 2091-2104.

Gutleben, J., De Mares, M. C., van Elsas, J. D., Smidt, H., Overmann, J. \& Sipkema, D. (2018). The multi-omics promise in context: from sequence to microbial isolate. Critical Reviews in Microbiology, 44(2), 212-229.

Hadadi, N., Pandey, V., Chiappino-Pepe, A., Morales, M., Gallart-Ayala, H., Mehl, F., Ivanisevic, J.,Sentchilo, V.\&van der Meer, J. R. (2020). Mechanistic insights into bacterial metabolic reprogramming from OMICs-integrated genome-scale models.npj Systems Biology andApplications, 6(1), 1-11.

Hammershoj, R., Birch, H., Redman, A. D. \& Mayer, P. (2019). Mixture effects on biodegradation kinetics of hydrocarbons in surface water: Increasing concentrations inhibited degradation whereas multiple substrates did not. Environmental Science \& Technology, 53(6), 3087-3094.

Haroon, M. F., Hu, S., Shi, Y., Imerlfort, M., Keller, J. \& Hugenholtz, P. (2013). Anaerobic oxidation of methane coupled to nitrate reduction in novel archaeal lineage. Nature, 500, 567-570.

Hatzenpichler, R., Connon, S. A., Goudeau, D., Malmstrom, R. R., Woyke, T. \& Orphan, V. J. (2016). Visualizing in situ translational activity for identifying and sorting slow-growing archaeal-bacterial consortia.Proceedings of the National Academy of Sciences of the USA, 113, Article E4069-E4078.

Hazrati, H., Shayegan, J. \& Sayedi, S. M. (2015). Biodegradation kinetics and interactions of styrene and ethylbenzene as single and dual substrates for a mixed bacterial culture. Journal of Environmental Health Science Engineering, 13, Article 72.

He, P., Liu, J., Bai, Y. \& Fang, X. (2016). Diversity and distribution of catechol 2,3-dioxygenase genes in surface sediments of the Bohai Sea. FEMS Microbiology Letters, 263(10), Article fnw086.

Henckel, T., Jackel, U., Schnell, S. \& Conrad, R. (2000). Molecular analyses of novel methanotrophic communities in forest soil that oxidize atmospheric methane. Applied Environmental Microbiology, 66,1801-1808.

Holtorf, H., Guitton, M-C \& Reski R. (2002). Plant functional genomics. The Science of Nature, 89(6), 235-249.

Huettel, M., Overholt, W. A., Kostka, J. E., Hagan, C., Kaba, J., Wells, W.B. \& Dudley, S. (2018). Degradation of Deepwater Horizon oil buried in a Florida beach influenced by tidal pumping. Marine Pollution Bulletin, 126, 488-500.

Igeno, M. I., Macias, D. \& Blasco, R. (2019). Case of adaptive laboratory evolution (ALE): Biodegradation of furfural by Pseudomonaspseudoalcaligenes CECT 5344. Genes, 10, 449.

Imperato, V., Portillo-Estrada, M., McAmmond, B. M., Douwen, Y., Van Hamme, J. D. \& Gawronski, S. W. (2019). Genomic diversity of two hydrocarbon-degrading and plant growth-promoting pseudomonas species isolated from the oil field of Bobrka (Poland). Genes, 10(6), Article 443.

Jiang, B., Jin, N., Xing, Y., Su, Y. \& Zhang, D. (2018). Unravelling uncultivable pesticide degraders via stable isotope probing (SIP). Critical Reviews in Biotechnology, 38(7), 1-24.

Joo, W. A. and Kim, C. W. (2005). Proteomics of halophilic archaea. Journal of Chromatography B: Analytical Technologies in Biomedical and Life Sciences, 815, 237-250.

Joye, S. \& Kostka, J. (2020) Microbial Genomics of the Global Ocean System. American Society for Microbiology. https://www.ncbi.nlm.nih.gov/books/ NBK556286/

Karthika, R., Gopinath, L. R., Archaya, S. \& Bhuvaneswan, R. (2014). Isolation of diesel degrading bacteria, identification of catechol gene and its biogas production. IOSR Journal of Environmental Science, Toxicology and Food Technology, 8, 76-82.

Karthikeyan, S., Rodriguez-R, L. M., HeritierRobbins, P., Kim, M., Overholt, W. A., Gaby, J. C., Hatt, J. K., Spain, J. C., Rosselló-Móra, R., Huettel, M., Kostka, J. E. \& Konstantinidis, K. T. (2019). "CandidatusMacondimonasdiazotrophic a", a novel gammaproteobacterial genus dominating crude-oilcontaminated coastal sediments.ISME Journal, 13, 2129-2134. 
Kaster, A-K. \& Sobol, M. S. (2020). Microbial single-cell omics: the crux of the matter. Applied Microbiology \& Biotechnology, 104, 8209-8220.

Khan, A. A., Wang, R. F. \& Cao, W. W. (2001). Molecular cloning, nucleotide sequence, and expression of genes encoding a polycyclic aromatic ring dioxygenase from Mycobacterium sp. strain PYR-1. Applied Environmental Microbiology, 67, 3577-85.

Kim, S. II, Kim, S. J. \& Nam, M. H. (2002). Proteome analysis of aniline-induced proteins in Acinetobacterlwoffi K24. Current Microbiology, 44,61-6.

Knigge, T., Monsinjon, T. \& Andersen, O. K. (2004). Surface-enhanced laser desorption/ionization-time of flightmass spectrometry approach to biomarker discovery in blue mussels (Mytilusedulis) exposed to polyaromatic hydrocarbons and heavy metals under field conditions. Proteomics, 4, 27222727.

Konneke, M., Bernhard, A. E., de la Torre, J. R., Walker, C. B., Waterbury, J. B. \& Stahl, D. A. (2005). Isolation of an autotrophic ammonia-oxidising marine archaeon. Nature, 7058, 543-546.

Krivobok, S., Kuony, S. \& Meyer, C. (2003). Identification of pyrene-induced proteins in Mycobacterium spp. strain 6PY1: evidence for two ringhydroxylating dioxygenases. Journal of Bacteriology, 185, 3828-3841.

Kuhner, S., Wohlbrand, L. and Fritz, I. (2005). Substrate-dependent regulation of anaerobic degradation pathways for toluene and ethylbenzene in a denitrifying bacterium, strain EbN1. Journal of Bacteriology, 187, 14931503.

Kumari, P. \& Kumar, Y. (2021). Chapter 19 Bioinformatics and computational tools in bioremediation and biodegradation of environmental pollutants. In V. Kumar, G. Sxena \& M. P. Shah (Eds). Bioremediation for environmental sustainability, 421-444.

Ladezma-Villaneuva, A., Adame-Rodriguez, J. M. \& Arechiga-carvajal, E. T. (2018). Transcriptomics as a first choice gate for fungal biodegradation process description. In R. Prasad \& E. Arande (Eds.), Approaches in bioremediation. Nanotechnology in the life sciences. Springer Cham.

Lederberg, J. \& McCray, A. T. (2001). Commentary: 'Ome Sweet 'Omics - A

UMYU Journal of Microbiology Research
Genealogical Treasury of Words. The Scientist, 15(7), 8.

Lemos, E. G. D. M., Alves, L. M. C. \& Campanharo, J. C. (2003). Genomics based design of defined growth media for the plant pathogen Xylellafastidiosa. FEMS Microbiology Letters, 219, 39-45.

Lilis, L., Clipson, N. \& Doyle, E. (2010). Quantification of catechol deoxygenase gene expression in soil during degradation of 2,4-dichlorophenol. FEMS Microbiology Ecology, 73(363), 9.

Lim, N. Y. N., Roco, C. A. \& Frostegard, A. (2016). Transparent DNA-RNA coextraction workflow protocol suitable for inhibitor-rich environmental samples that focuses on complete DNA removal for transcriptomic analyses. Frontiers in Microbiology, 7, 1588.

Liu, Z. \& Liu, J. (2013). Evaluating bacterial community structures in oil collected from the sea surface and sediment in the northern Gulf of Mexico after the Deepwater Horizon oil spill. Microbiologyopen, 2, 492-504.

Lovely D. R. (2003). Cleaning up with genomics: applying molecular biology to bioremediation. Nature Reviews Microbiology, 1, 35-44.

Ma, J. \& Zhai, G. (2012). Microbial bioremediation in Omics era: opportunitiesand challenges. Journal of Bioremediation and Biodegradation, 3, Article $e 120$.

Marchesi, J. R. \& Ravel, J. (2015). The vocabulary of microbiome research: a proposal. Microbiome, 3, 31.

Mason, O. U., Hazen, T. C., Borglin, S., Chain, P. S., Dubinsky, E. A., Fortney, J. L., Han, J., Holman, H. Y., Hultman, J., Lamendella, R., Mackelprang, R., Malfatti, S., Tom, L. M., Tringe, S. G., Woyke, T., Zhou, J., Rubin, E. M. \& Jansson, J. K. (2012). Metagenome, metatranscriptome and single-cell sequencing reveal microbial response to Deepwater Horizon oil spill. ISME Journal, 6, 1715- 1727.

McDonald, I. R., Miguez, C. B., Rogge, G., Bourque, D., Wendlandt, K. D., Groleau, D. \& Murrel, J. (2006). Diversity of soluble methane monooxygenase-containing methanotrophs isolated from polluted environments. FEMS Microbiology Letters, 255(2), 1722-1732.

McLean, T. I. (2013). "Eco-omics": A review of the application of genomics, transcriptomics and proteomics for the www.ujmr.umyu.edu.ng 
study of the ecology of harmful algae. Microbial Ecology, 65, 901-915.

Musa, S.I. (2019). Isolation and identification of diesel oil-degrading bacteria in used engine oil contaminated soil. Journal of Applied Science and Environmental Management, 23, 431-435.

Namasivayam, E.(2013). Proteomics: techniques, applications and challenges. In: D. Barh, Y. Zambare and V. Azevedo (Eds.). OMICS. Applications in biomedical, agricultural and environmental sciences. $\left(1^{\text {st }}\right.$ ed., pp. 342). CRC Press/Taylor and Francis.

Nikhil, T., Deepa, V., Rohan, G. and Satish, B. (2013). Isolation, characterization and identification of bacteria from garage soil and comparison of their bioremediation potential. International Research Journal of Environment Sciences, 2, 48-50.

O'Connell, M. J., McNally, A. \& Mclnerney, J. O. (2017). Why prokaryotes have pangenomes. Nature Microbiology, 2(4), Article 17040.

Overmann, J.(2010). Novel cultivation strategies for environmentally important microorganisms. In: L. L. Barton, M. Mandle\&A. Loy, (Eds). Geomicrobiology: molecular and environmental perspective ( $1^{\text {st }}$ ed., pp. 69-89). Springer.

Overmann, J., Abt, B. \& Sikorski, J. (2017). Present and future of culturing bacteria. Annual Review of Microbiology, 71, 71-730.

Oyewusi, H. A., Abdul Wahab, R. \& Huyop, F. (2021). Whole genome strategies and bioremediation insight into dehalogenase-producing bacteria. Molecular Biology Reports, 48, 26872701.

Pan. Y., Kong, K. F. \& Tsang, J. S. (2015). Complete genome sequence and characterisation of the haloaciddegrading Burkholderia caribensis MBA4. Standards in Genomic Sciences, 10(1), Article 114.

Paoletti, A. C., Zybailov, B. and Washburn, M. P.(2004). Principles and applications of multidimensional protein identification technology. Expert Reviews inProteomics, 1, 275-282.

Plewniak, F., Crognale, S., Rosetti, S. \& Berin, P. N. (2018). A genomic outlook on bioremediation: The case of arsenic removal. Frontiers in Microbiology, 9, Article 820.

Qiao, J., Zhang, C., Luo, S. \& Chen, W. (2013). Bioremediation of highly contaminated

UMYU Journal of Microbiology Research oil field soil: Bioaugmentation for enhancing aromatic compounds removal. Frontiers in Environmental Science and Engineering, 8, 296-304.

Rathoure, A. \& V. Dhatwalia (Eds.), Toxicity and waste management using bioremediation ( $1^{\text {st }}$ ed.). IGI Global.

Rehman, Z.U., Khan, K., Faisal, S., Kamal, R., Ahmad, S., Irfan, M.K.H., Safa, I. U. \& Kumar, T. (2015). Isolation and identification of diesel degrading bacteria from oil contaminated soil in Mansehra, Pakistan. International Journal of Scientific and Engineering Research, 6, 1438-1661.

Rodriguez-R., L., Overholt, W., Hagan, C., Huettel, M., Kostka, J. E.\& Konstantinidis, K. T.(2015). Microbial community successional patterns in beach sands impacted by the Deepwater Horizon oil spill. ISMEJournal, 9, 1928-1940.

Roling, W. F., Ferrer, M. \& Golyshin, P. N. (2010). Systems approach to microbial communities and their functioning. Current Opinion in Biotechnology, 21, 532-538.

Salvador, M., Abdulmutallib, U., Gonzalez, J., Kim, J., Smith, A. A., Faulon J-P., Wei, R., Zimmerman, W. \& Jiminez, J-I. (2019). Microbial genes for a circular and sustainable bio-PET economy. Genes, 10, Article 373.

Santero, E. \& Diaz, E. (2020). Special issue: Genetics of biodegradation and bioremediation. Genes, 11(4), Article 441.

Santos, P. M., Benndorf, D.\& Sa-Correia, I. (2004). Insights into Pseudomonasputida KT2440 response to phenol-induced stress by quantitative proteomics. Proteomics, 4, 2640-52.

Schao, H., Chen, M. \& Fei, X. (2019). Complete genome sequence and characterisation of a polyethylene biodegradation strain, Streptomycesalbogriseolus LBX2. Microorganisms, 7, 10, 379.

Schleper, C., Jurgens, G. \& Jonuscheit, M. (2005). Genomic studies of uncultivated archaea. Nature Reviews Microbiology, 3, 479-488.

Seifert, J., Herbst, F. A., Halkjaer-Nielsen, P. \& Planes, J. F. (2013). Progress and applications in metaproteogenomics for bridging the gap between genomic sequences and metabolic functions in microbial communities. Proteomics, 13, 2786-2804.

Seshadri, R., Adrian, L. \& Fouts, D.E. (2005). Genome sequence of the PCE-

$$
\text { www.ujmr.umyu.edu.ng }
$$


dechlorinating

bacterium

Dehalococcoidesethenogenes.Science, 3 07, 105-108.

Shiller, A. M., Chan, E. W., Joung, D. J., Redmond, M. C. \& Kessler, J. D. (2017). Light rare earth element depletion during Deepwater Horizon blowout methanotrophy. ScientificReports,7(1), 1-9.

Shin, B., Kim, M., Zengler, K., Chin, K. J., Overholt, W. A., Gieg, L. M.\&Konstantinidis, K. T. (2019). Anaerobic degradation of hexadecane and phenanthrene coupled to sulfate reduction by enriched consortia from northern Gulf of Mexico seafloor sediment.ScientificReports,9, Article 1239.

Singh, C. \& Lin, J. (2008). Isolation and characterization of diesel oil degrading indigenous microorganismsin KwazuluNatal,SouthAfrica. African Journal of Biotechnology,7, 1927-1932.

Singh, J. S. \& Singh, D. P. (2017). Methanotrophs: An emerging bioremediation tool with unique broad spectrum methane monooxygenase (MMO) enzyme. In J. Singh \& G. Seneviratne (Eds.). Agro-Environmental Sustainability $\left(1^{\text {st }}\right.$ Ed., pp 1-18). Springer Cham.

Singh, O. V. \& Nagaraj, N. S. (2015). Transcriptomics, proteomics and interactomics: unique approaches to track the insights of bioremediation. Briefings in Functional Genomics and Proteomics, 4(4), 355-362.

Thulasi, K., Jayakumar, A., Balakrishna-Pillai, A., GopalakrishnapallaiSankaramangalam, V. K. \& Kumarapillai, H. (2018). Efficient methanol-degrading aerobic bacteria isolated from a wetland ecosystem. Archives of Microbiology, 200(5), 829853.

Tyson, G. W., Lo, I., Baker, B. J., Allen, E. E., Hugenhotz, P. \& Banfield, J. F. (2005). Genome-directed isolation of the key nitrogen fixer Leptosprillumferrodiazotrophum sp. Nov. from an acidophilic microbial community. Applied Environmental Microbiology, 71, 6319-6324.

Ullrich, S. R., Poehlein, A., Tieschler, J. S., Gonzalez, C., Ossandon, F. J. \& Daniel, R. (2016). Genome analysis of the biotechnologically relevant acidophilic iron oxidising strain JA12 indicates phylogenetic and metabolic diversity within the novel genus "Ferrovum" PLoS One, 11(1), Article e0146832.

Umar, Z.D., Aminu, M., Yahaya, Y.R. (2020a). Survival response of Consortium isolates from diesel contaminated soil within Katsina State, Nigeria. International Journal of Environment. 9: 51-66.

Umar, Z. D., Aminu, M. \& Yahaya, Y.R. (2020b). Optimization of Diesel biodegrading conditions using Response Surface Methodology based on Central Composite Design. Polycyclic Aromatic Compounds, 40, 1-11.

Umar, Z.D., Mansir, A.Z., \& Riko, Y.Y. (2019). Compatibility and formulation of diesel degrading consortia using bacteria isolated from contaminated soil. Bayero Journal of Pure and Applied Sciences, 12(1), 199-208.

Umar, Z.D., Aziz, N.A.A., Zulkifli, S .Z. and Mustafa, M.(2018a). Efficiency of polycyclic aromatic hydrocarbons (PAHs) degrading consortium in resisting heavy metals during PAHs degradation. International Journal of Environment, 7(1), 14-27.

Umar, Z.D., Azwady, A.A.N, Zulkifli, S. Z. \& Muskhazli, M.(2018b). Effective Phenanthrene and Pyrene biodegradation using Enterobacter sp. MM087 (KT933254) isolated from used engine oil contaminated soil. Egyptian Journal of Petroleum,27(3), 349-359.

Umar, Z.D., Abd. Aziz, N.A., Zulkifli, S.Z. and Mustafa, M. (2017). Rapid Biodegradation of Polycyclic Aromatic Hydrocarbons Using Effective Cronobacter sakazakii MM045 (KT933253), MethodsX, 4, 104-117.

Umar, Z.D. (2017). Biodegradation of Phenanthrene and Pyrene using Bacteria isolated from used vehicle lubricant-contaminated soil. Doctoral Thesis (PhD). Published by Universiti Putra Malaysia Institutional repository (UPMIR). Pages 1-172. http: //psasir.upm.edu.my/id/eprint/7 $1027 /$

Umar, Z.D., Aziz, N.A.A., Zulkefli, S.Z. and Muskhazli, M. (2016). Identification of phenanthrene and pyrene degrading bacteria from used engine oil contaminated soil. International Journal of Scientific and Engineering Research, 7, 680-686.

Umar, Z.D., and Bashir, A. (2014): Assessment of potential health impacts on surface water sources in Northern Nigeria. International Journal of Environment, 
$3(2)$,

152-163.

doi: $10.3126 /$ ije.v3i2.10523

Vakhlu, J. \& Gupta, P.(2013). Metagonomics: techniques, applications and challenges. In B. D. Barh, Y. Zambare, Y. \&V. Azevedo (Eds.). OMICS. Applications in Biomedical, Agricultural and Environmental Sciences. $\left(1^{\text {st }}\right.$ ed., pp 569596). CRC Press/Taylor and Francis.

Vonk, S. M., Hollander, D. J.\&Murk, A. J. (2015). Was the extreme and wide-spread marine oil-snow sedimentation and flocculent accumulation (MOSSFA) event during the Deepwater Horizon blow-out unique? Marine Pollution Bulletin, 100, 512.

Wang, J., Suzuki, T., Dohra, H., Mori, T., Kawagishi, H. \& Hirai, H. (2020). Transcriptomics analysis reveals the high biodegradation efficiency of white-rot fungus Phanerochaetae sordida YK-624 on native lignin. ResearchSquare. https: / / www.researchsquare.com/article .rs-11087/v1

Wang, R. F., Wennerstrom, D. \& Cao, W. W. (2000). Cloning, expression, and characterization of the katG gene, encoding catalase-peroxidase, from the polycyclic aromatic hydrocarbondegrading bacterium Mycobacterium sp. strain PYR-1. Applied Environmental Microbiology, 66, 4300-4304.

Wasinger, V. C., Cordwell, S. J. \& CerpaPoljak, A. (1995). Progress with geneproduct mapping of the Mollicutes: Mycoplasmagenitalium. Electrophoresis, 16, 1090-1094.

Weiman, S., Joye, S. B., Kostka, J. E., Halanych, K. M. \& Colwell, R. R. (2021). GoMRI insights into microbial genomics and hydrocarbon bioremediation response in marine ecosystems. Chromatography, 34(1), 124-135.

Wilkins, J.C., Homer, K. A. \& Beighton, D. (2001). Altered protein expression of Streptococcus oralis cultured at low $\mathrm{pH}$ revealed by two-dimensional gel electrophoresis. Applied Environmental Microbiology, 67, 3396-3405.

Wood, T. K.(2008). Molecular approaches in bioremediation. Current Opinion in Biotechnology, 19, 572-578.

Woyke, T., Doud, D. F. R. \& Schultz, F. (2017). The trajectory of microbial single-cell sequencing. Nature Methods, 14, 10451054.

Wright, C. L., Schatterman, A., Crombie, A. T., Murelli, J. C. \& Lehtovirta-Morley, L. E.
(2020). Inhibition of ammonia monooxygenase from ammonia-oxidising archaea by linear and aromatic alkynes. Applied and Environmental Microbiology, 86(9), Article e02388-19.

Xiang, W., Wei, X., Tang, H., Li, L. \& Huang, R. (2020). Complete genome sequence and biodegradation characteristics of benzoicacid degrading bacterium Pseudomonas sp. SCB32. Biomed Research International, 2020, Article 6146104.

Xu, Y. \& Zhao, F. (2018). Single-cell metagonomics: Challenges and applications. Protein Cell 9, 501-510.

Ye, R. W., Tao, W. \& Bedzyk, L. (2000). Global gene expression profiles of Bacillussubtilis grown under anaerobic conditions. Journal of Bacteriology, 182, 4458-4465.

Yetti, E., Wijaya, H., Thontowi, A. \&Yopi, A. (2016). Isolation of oil degrading bacteria from the terrestrial sitesof Minas, Riau and the prescreening of the isolates on thesimple polycyclic aromatic hydrocarbon. Proceedings of the 6th International Symposium for Sustainable Humanosphere, 237-243.

Yoneda, A., Henson, W. R., Goldner, N. K., Park, K. J., Fosberg, K. J. \& Kim, S. J. (2016). Comparative transcriptomics elucidates adaptive phenol tolerance and utilization in lipid-accumulating Rhodococcusopacus PD630. Nucleic Acids Research, 44, 2240-2254.

Zampoli, J., Di Canito, A., Manconi, A., Milanesi, L., Di Gennaro, P. \& Orro, A. (2020). Transcriptomic analysis of Rhodococcus opacusR7 grown on o-xylene by RNA-seq. Frontiers in Microbiology, 11, Article 1808.

Zhao, B. \& Poh, C. L. (2008). Insights into environmental bioremediation by microorganisms through functional genomics and proteomics. Proteomics, 8(4), 874-881.

Zhou, J. \& Fields, M. (2006). Application of OMICs to Field Bioremediation: Current Status, Challenges and Future.https://doesbr.org/PImeetings/A pril06/presentationts/Tuesday_ERSP/Sum mary_Zhou_Fields.pdf

Ziervogel,K., McKay, L., Rhodes, B., Osburn, C. L., Dickson-Brown, J., Arnosti, C.\& Teske, A. (2012). Microbial activities and dissolved organic matter dynamics in oilcontaminated surface seawater from the Deepwater Horizon oil spill site. PLoS One, 7, Article e34816. 